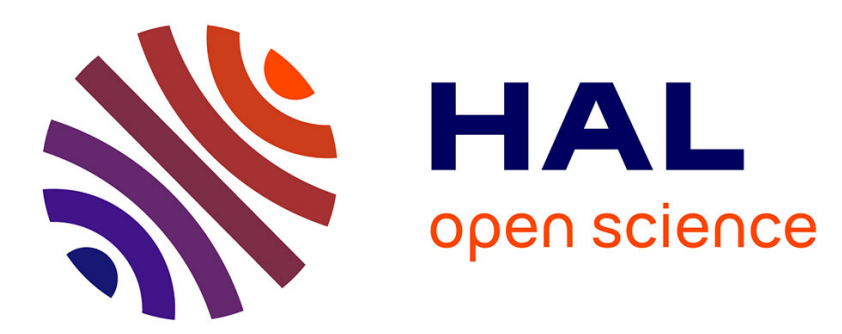

\title{
Distribution of aflatoxins and fumonisins in dry-milled maize fractions
}

\author{
Amedeo Pietri, Marco Zanetti, Terenzio Bertuzzi
}

\section{To cite this version:}

Amedeo Pietri, Marco Zanetti, Terenzio Bertuzzi. Distribution of aflatoxins and fumonisins in dry-milled maize fractions. Food Additives and Contaminants, 2009, 26 (03), pp.372-380. 10.1080/02652030802441513 . hal-00577336

\section{HAL Id: hal-00577336 https://hal.science/hal-00577336}

Submitted on 17 Mar 2011

HAL is a multi-disciplinary open access archive for the deposit and dissemination of scientific research documents, whether they are published or not. The documents may come from teaching and research institutions in France or abroad, or from public or private research centers.
L'archive ouverte pluridisciplinaire HAL, est destinée au dépôt et à la diffusion de documents scientifiques de niveau recherche, publiés ou non, émanant des établissements d'enseignement et de recherche français ou étrangers, des laboratoires publics ou privés. 


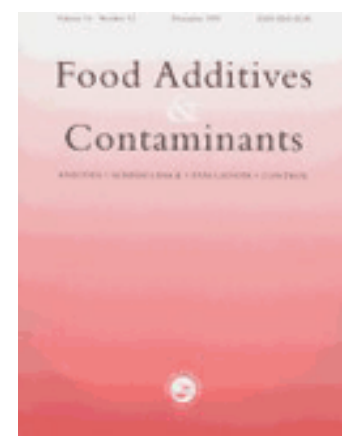

\section{Distribution of aflatoxins and fumonisins in dry-milled maize fractions}

\begin{tabular}{|r|l|}
\hline Journal: & Food Additives and Contaminants \\
\hline Manuscript ID: & TFAC-2008-158.R1 \\
\hline Manuscript Type: & Original Research Paper \\
\hline Date Submitted by the & 20-Aug-2008 \\
\hline Complete List of Authors: & $\begin{array}{l}\text { Pietri, Amedeo; Università Cattolica del Sacro Cuore, Scienze degli } \\
\text { alimenti e della nutrizione } \\
\text { Zanetti, Marco; Università Cattolica del Sacro Cuore, Scienze degli } \\
\text { alimenti e della nutrizione } \\
\text { Bertuzzi, Terenzio; Università Cattolica del Sacro Cuore, Scienze } \\
\text { degli alimenti e della nutrizione }\end{array}$ \\
\hline Methods/Techniques: & $\begin{array}{l}\text { Chromatography - HPLC, Chromatography - LC/MS, Clean-up - } \\
\text { affinity columns }\end{array}$ \\
\hline Additives/Contaminants: & Aflatoxins, Fumonisins \\
\hline Food Types: & Cereals, Processed foods \\
\hline &
\end{tabular}

\section{SCHOLARONE ${ }^{\text {M }}$ Manuscripts}




\title{
Distribution of aflatoxins and fumonisins in dry-milled maize fractions
}

\author{
A. Pietri, M. Zanetti and T. Bertuzzi \\ Istituto Scienze degli Alimenti e della Nutrizione, Facoltà di Agraria, Università \\ Cattolica del Sacro Cuore, Via Emilia Parmense, 84 I-29100 Piacenza, Italy \\ E-mail: amedeo.pietri@unicatt.it
}

\begin{abstract}
The aim of this study was to evaluate the distribution of aflatoxins and fumonisins in fractions derived from dry-milling of contaminated maize. Two maize lots with different contamination levels were processed and sampled: the first (maize 1) had aflatoxin $\mathrm{B}_{1}\left(\mathrm{AFB}_{1}\right)$ and fumonisin $\mathrm{B}_{1}\left(\mathrm{FB}_{1}\right)$ levels of 3.6 and $5379 \mu \mathrm{g} \mathrm{kg}^{-1}$, respectively; the second (maize 2) had corresponding levels of 91.1 and $8841 \mu \mathrm{g} \mathrm{kg}^{-1}$, respectively. The cleaning step reduced $\mathrm{AFB}_{1}$ and $\mathrm{FB}_{1}$ levels by 8 and $11 \%$ in maize 1 and by 57 and $34 \%$ in maize 2 . The subsequent removal of bran and germ led to a further decrease in contamination levels in the products destined for human consumption. In the latter, $\mathrm{AFB}_{1}$ was uniformly distributed, while $\mathrm{FB}_{1}$ was concentrated in the finer size fractions. Contamination of raw maize $1\left(3.6 \mu \mathrm{g} \mathrm{kg}^{-1}\right)$ was below the $\mathrm{EU} \mathrm{AFB}_{1}$ limit of $5 \mu \mathrm{g} \mathrm{kg}^{-1}$ for unprocessed maize, but among the final products only coarse flour $\left(1.7 \mu \mathrm{g} \mathrm{kg}^{-1}\right)$ was within the EU limit of $2 \mu \mathrm{g} \mathrm{kg}^{-1}$, while grits and fine flour showed higher levels (2.7 and $2.5 \mu \mathrm{g} \mathrm{kg}^{-1}$, respectively). As regards
\end{abstract}


cleaned maize, a different distribution of the two toxins was observed in the kernels: $\mathrm{AFB}_{1}$ contamination was more superficial and concentrated in germ, while $\mathrm{FB}_{1}$ contamination affected the inner layers of the kernels.

Keywords: aflatoxins, fumonisins, maize, dry-milling process, milling fractions

\section{Introduction}

Maize is one of the most important agricultural crops in the world, both for its potential yield per hectare and its nutritional value. In Italy, the area dedicated to maize cultivation is about 1.1 million hectares, located mainly in Northern Italy, while maize production is about 9.7 million tonnes (Istat, 2006). Although grown principally for animal feed, about $4 \%$ of Italian maize production is destined for the milling industry and is processed into products for human consumption.

The natural occurrence in maize of mycotoxins such as aflatoxins, fumonisins, trichothecenes and zearalenone, has been reported in various studies (Vargas et al. 2001; Adejumo et al. 2007; Abbas et al. 2002; Ali et al. 1998; Domijan et al. 2005; Gonzalez et al. 1999). As regards maize produced in Italy, mycotoxins that deserve special attention are: aflatoxins for their extreme acute and chronic toxicity and because a toxic metabolite (aflatoxin $\mathrm{M}_{1}$ ) is excreted into the milk of cows fed contaminated feeds; fumonisins for their toxicity and high and widespread contamination that cause several disease states in animals and could affect human health (Pietri et al. 2004; Logrieco et al. 2002; Battilani et al. 2005). Aflatoxins $B_{1}, B_{2}, G_{1}$ and $G_{2}$ are mainly produced by two fungal species: Aspergillus flavus and A. parasiticus, mould species that grow in 
warm conditions in tropical and sub-tropical regions of the world. Aflatoxin $\mathrm{B}_{1},\left(\mathrm{AFB}_{1}\right)$ the most toxic aflatoxin, is a potent genotoxic carcinogen in laboratory animals and there is strong evidence that it is a liver carcinogen in humans. Fumonisins $B_{1}, B_{2}$ and $\mathrm{B}_{3}$ are a group of closely related compounds mainly produced by Fusarium verticillioides and $F$. proliferatum, fungi that commonly contaminate maize in many growing regions of the world; studies demonstrate the importance of insect damage, drought and temperature stress on fumonisin synthesis. Fumonisins have been shown to be hepatocarcinogenic in male rats and female mice and nephrocarcinogenic in male rats (Voss et al. 2001). Fumonisins have also been associated with the high incidence of human oesophageal cancer in some regions of South Africa and China (Sydenham et al. 1990; Sun et al. 2007). Recent findings suggest that they might increase the risk of neural tube defects in populations consuming large amounts of fumonisin-contaminated maize (Missmer et al. 2006).

Aflatoxin $\mathrm{B}_{1}$ and Fusarium verticillioides toxins have been categorised by the International Agency for Research on Cancer (IARC) as class 1 (human carcinogen) and 2B (possible human carcinogen), respectively (IARC 1993). In a later evaluation in 2002, the IARC declared fumonisin $\mathrm{B}_{1}\left(\mathrm{FB}_{1}\right)$ to be a group $2 \mathrm{~B}$ carcinogen (IARC 2002). The EU legislation fixed maximum admissible levels for $\mathrm{AFB}_{1}$, total aflatoxins (sum of $\mathrm{AFB}_{1}, \mathrm{AFB}_{2}, \mathrm{AFG}_{1}$ and $\mathrm{AFG}_{2}$ ) and fumonisins (sum of $\mathrm{FB}_{1}$ and $\mathrm{FB}_{2}$ ) in cereals and derived products for direct human consumption (Commission of the European Communities 2006a, 2007). Current limits relevant to maize are given in Table 1. Current legislation being very detailed, for maize millers it is vital to know the extent of decontamination that can be obtained by the first step (cleaning) of the process and how 
these mycotoxins are distributed in final products. Physical procedures generate little heat other than that caused by the operation of the machinery for cleaning, de-husking and abrasion so no significant thermal breakdown of mycotoxins would be expected at this stage. However, moulds and mycotoxins are often concentrated in dust and broken grains or in the outer seed coat of grains. The removal of this material can thus result in a considerable reduction of the mean mycotoxin concentration.

Fumonisin distribution was studied on a laboratory-scale processing apparatus (Katta et al. 1997) or sampling, over 9 months, maize products in a commercial dry-mill (Broggi et al. 2002). Brera et al. (2004, 2006) carried out a study, in a commercial dry-milling plant, of $\mathrm{FB}_{1}$, aflatoxins and zearalenone distribution in milled corn fractions from two maize lots showing medium-low contamination levels. These studies indicated that contamination increased, with respect to unprocessed maize, in products like bran, germ and flour of low particle size (animal feed flour), while it decreased in grits and flour of higher particle size, destined for human consumption. No data are available on the effect of the cleaning step.

The aim of our work was to investigate in an industrial dry-mill: (a) aflatoxin and fumonisin distribution in milling products deriving from the processing of two maize lots, that showed (with respect to the Italian situation) medium levels of aflatoxins $\left(\mathrm{AFB}_{1}, \mathrm{AFB}_{2}, \mathrm{AFG}_{1}, \mathrm{AFG}_{2}\right)$ and fumonisins $\left(\mathrm{FB}_{1}\right.$ and $\left.\mathrm{FB}_{2}\right)$ in the first and high levels in the second (about 5 and $8000 \mu \mathrm{g} \mathrm{kg}^{-1}$ for the first lot, 120 and $13000 \mu \mathrm{g} \mathrm{kg}^{-1}$ for the second, respectively); (b) the efficacy of maize cleaning steps, carried out at the beginning of the process, on aflatoxin and fumonisin contamination levels. Further, a 
[insert Table 1 about here]

\section{Materials and methods \\ Dry-Milling Process}

The study was carried out in an industrial dry-milling plant able to process 10 tonnes per hour of maize grain and performed de-germination under partially wet conditions by a conical de-germinator. First, the unprocessed maize was cleaned through three different steps (Figure 1), which included a separator with aspirator (winnower), a dry de-stoner and an intensive scourer coupled with an aspirator. The cleaned maize was soaked in warm water $\left(70^{\circ} \mathrm{C}\right)$ for $10 \mathrm{~min}$, to increase moisture to $22 \%$. In these conditions, the germ becomes soft and elastic; also, partial detachment of bran occurs. After soaking, the maize was decorticated and de-germinated in the conical degerminator, then sifted through a 5-mm sieve. The fraction (large size grits and germ) retained on the sieve was directly conveyed to the plan sifter, while the sieved fraction (flours, bran, small size grits and fractions of germ) was dried to $14 \%$ moisture content and conveyed to a turbo-sifter, where the flour of a particle size $<2 \mathrm{~mm}$ (fine flour), was separated and destined to animal feed. The fraction with a particle size $>2 \mathrm{~mm}$ was conveyed to a winnower, which aspirated the bran (lighter) sending it to animal feed, while fractions of germ and small size grits were sent to the plan sifter, together with large size grits and germ of particle size $>5 \mathrm{~mm}$. The plan sifter separated the products according to their size: those of size $>5.5 \mathrm{~mm}$, were conveyed back to the de- 
germinator, while the smaller ones were separated through a $4 \mathrm{~mm}$ sieve. The fractions which were obtained were sent to different gravity tables, to separate germ from small and large size grits. Fine grits were processed again using a horizontal roller mill and transformed into flour, that was conveyed to a plan sifter and divided between coarse flour $(300-850 \mu \mathrm{m})$, fine flour $(<300 \mu \mathrm{m})$ and residual germ (about $1 \%)$. Undersized flour, bran and cleaning waste, were processed with a hammer mill for the production of animal feed flour.

[insert Figure 1 about here]

\section{Samples}

Two maize lots (maize 1 and 2), with different aflatoxin and fumonisin contamination, were processed and sampled. Both were FAO 600 class hybrids, with flinty endosperm. Samples of unprocessed maize and derived fractions were drawn from twelve opening slits of the plant (numbered in Figure 1). In order to obtain a dynamic representative sampling (corresponding to the flow of different products), a primary sample of about $300 \mathrm{~g}$ was collected from each slit every 90 seconds for one hour (40 samples), according to the Regulation 2006/401/EC (Commission of the European Communities 2006b). From the cleaning plant were collected: unprocessed maize (1), waste of the winnower (2), of the dust filter (3), of the intensive scourer (4) and cleaned maize (5). From the de-germination process were collected: bran (6), germ (7), coarse grits (8), fine grits (9) and animal feed flour (12). From the refining step were collected: coarse (10) and fine flour (11). For each collecting-slit, the 40 primary samples were mixed, ground with a hammer mill (1 $\mathrm{mm}$ sieve), and homogenized for $10 \mathrm{~min}$ using a 


\section{Analytical Standards}

Aflatoxin and fumonisin standards were obtained from Sigma-Aldrich (St. Louis, MO, USA). For each aflatoxin, a stock solution of 5-8 $\mu \mathrm{g} \mathrm{ml} \mathrm{m}^{-1}$ was prepared in benzene:acetonitrile $(98: 2, \mathrm{v} / \mathrm{v}, 2 \mathrm{ml})$ and stored at $-20^{\circ} \mathrm{C}$. The solution was calibrated spectrophotometrically at $350 \mathrm{~nm}$ (AOAC International, 2005). The working standard solution was prepared after evaporation under nitrogen of an aliquot $(100 \mu \mathrm{l})$ of the stock solution and re-dissolution in chloroform $(10 \mathrm{ml})$ by ultrasonication. An aliquot $(100 \mu \mathrm{l})$ of this solution was evaporated under nitrogen and re-dissolved in the HPLC mobile phase $(0.5-5 \mathrm{ml})$, to obtain calibrant solutions at individual concentrations of $\mathrm{AFB}_{1}, \mathrm{AFB}_{2}, \mathrm{AFG}_{1}, \mathrm{AFG}_{2}$ between 0.3 and $6 \mu \mathrm{g} \mathrm{l}^{-1} . \mathrm{FB}_{1}$ and $\mathrm{FB}_{2}(1 \mathrm{mg})$ were separately dissolved in $10 \mathrm{ml}$ acetonitrile:water $(1: 1, \mathrm{v} / \mathrm{v})$; the concentration was calculated using the weight indicated by the manufacturer. These solutions were diluted to obtain HPLC calibrant solutions in acetonitrile:water $(30: 70, \mathrm{v} / \mathrm{v}$, acidified with $0.4 \%$ acetic acid) at individual concentrations of $\mathrm{FB}_{1}$ and $\mathrm{FB}_{2}$ between 2.5 and $50 \mu \mathrm{g}^{-1}$.

\section{Analysis for aflatoxins and fumonisins}

Aflatoxins were analysed according to the method of Stroka et al. (1999). Aflatoxins were extracted from $25 \mathrm{~g}$ of sample with $250 \mathrm{ml}$ methanol:water $(80: 20, \mathrm{v} / \mathrm{v})$, using a 
rotary-shaking stirrer for $45 \mathrm{~min}$. After filtration through a folded filter-paper, an aliquot of the filtrate $(5 \mathrm{ml})$ was diluted with distilled water $(45 \mathrm{ml})$ and the solution was purified through an immunoaffinity column (R-Biopharm Rhône LTD, Glasgow, Scotland, UK). After washing of the column with $5 \mathrm{ml}$ distilled water, aflatoxins were eluted into a graduated glass vial with methanol $(2.5 \mathrm{ml})$. The eluate, concentrated to 1.0 $\mathrm{ml}$ under a gentle stream of nitrogen, was brought to $2 \mathrm{ml}$ with acetonitrile:water $(25: 75, \mathrm{v} / \mathrm{v})$, and vortex-mixed for a few seconds; then, the extract was filtered (Millipore Corporation, Bedford, Massachussetts, USA, HV $0.45 \mu \mathrm{m}$ ) and injected (30 $\mu \mathrm{l})$. Analysis was performed using an HPLC instrument, consisting of two PU-1580 chromatographic pumps, an AS 1555 sampling system, a FP 1520 fluorescence detector and a post-column derivatization system (Jasco Corporation, Tokyo, Japan); the instrument was controlled by Borwin 1.5 software (Jasco). A Superspher RP-18 column ( $4 \mu \mathrm{m}$ particle size, $125 \times 4 \mathrm{~mm}$ i.d., Merck) was used at ambient temperature, with a mobile phase of water:methanol:acetonitrile $(64: 23: 13, \mathrm{v} / \mathrm{v} / \mathrm{v})$, at $1.0 \mathrm{ml} \mathrm{min}^{-1}$. A solution of pyridinium bromide perbromide (25 $\mathrm{mg}$ in $500 \mathrm{ml}$ of HPLC-grade water) was used as a derivatizing agent. The flow of the post-column derivatizing solution was set at $0.1 \mathrm{ml} \mathrm{min}^{-1}$ and the reaction tubing was $500 \mu \mathrm{l}$. The detector was set at $\lambda_{\mathrm{ex}}=365$ $\mathrm{nm}$ and $\lambda_{\mathrm{em}}=440 \mathrm{~nm}$.

$\mathrm{FB}_{1}$ and $\mathrm{FB}_{2}$ content was analysed according to the method proposed by Visconti et al. (2001). Fumonisins were extracted from $10 \mathrm{~g}$ of sample in a plastic centrifuge bottle with $50 \mathrm{ml}$ of acetonitrile:methanol:water $(25: 25: 50, \mathrm{v} / \mathrm{v} / \mathrm{v})$. After extraction for $45 \mathrm{~min}$ using a rotary-shaking stirrer and centrifugation at $4500 \mathrm{~g}$ for $6 \mathrm{~min}$, the supernatant was poured into a flask; another $50 \mathrm{ml}$ of the same solution was added to the residue in 
the centrifuge bottle, and a second extraction performed for $30 \mathrm{~min}$. The combined extracts were filtered through a folded filter-paper. An aliquot of $2 \mathrm{ml}$ was diluted with $20 \mathrm{ml}$ of $0.1 \mathrm{M}$ phosphate buffered saline (PBS, $\mathrm{pH}=7.4$ ) and purified through an immunoaffinity column (R-Biopharm Rhône Ltd, Glasgow, Scotland, UK); after washing the column with PBS $(2 \mathrm{ml})$, the fumonisins were slowly eluted $\left(0.5 \mathrm{ml} \mathrm{min}^{-1}\right)$ with methanol $(6 \mathrm{ml})$ into a graduated glass vial; subsequently, the eluate was concentrated to $2 \mathrm{ml}$ under a gentle stream of nitrogen. Analysis was carried out using a LC-MS/MS system, consisting of a LC 1.4 Surveyor pump (Thermo-Fisher Scientific, San Jose, CA, USA), a PAL 1.3.1 sampling system (CTC Analitycs AG, Zwingen, Switzerland) and a Quantum Discovery Max triple-quadrupole mass spectrometer; the system was controlled by Excalibur 1.4 software (Thermo-Fisher). After dilution of the extract $(0.1 \mathrm{ml}$ brought to $1 \mathrm{ml})$ with acetonitrile:water $(30: 70 \mathrm{v} / \mathrm{v}$, acidified with $0.4 \%$ acetic acid), the fumonisins were separated on a Betasil RP-18 column ( $5 \mu \mathrm{m}$ particle size, $150 \times 2.1 \mathrm{~mm}$, Thermo-Fisher) with mobile-phase gradient acetonitrile-water (both acidified with $0.4 \%$ acetic acid) from $25: 75$ to $55: 45$ in 9 min, then isocratic for 3 min; the flow rate was $0.2 \mathrm{ml} \mathrm{min}^{-1}$. Ionisation was carried out with an ESI interface (Thermo-Fisher) in positive mode as follows: spray capillary voltage $4.0 \mathrm{kV}$, sheath and auxiliary gas 35 and 14 psi, respectively, temperature of the heated capillary $270{ }^{\circ} \mathrm{C}$. The mass spectrometric analysis was operated in selected reaction monitoring (SRM). For fragmentation of $[\mathrm{M}+\mathrm{H}]^{+}$ions $\left(722 \mathrm{~m} / \mathrm{z}\right.$ for $\mathrm{FB}_{1}, 706 \mathrm{~m} / \mathrm{z}$ for $\left.\mathrm{FB}_{2}\right)$, the argon collision pressure was set to 1.5 mTorr and the collision energy to $36 \mathrm{~V}$. The selected fragment ions were: 704, 352 and $334 \mathrm{~m} / \mathrm{z}$ for $\mathrm{FB}_{1}, 688,336$ and $318 \mathrm{~m} / \mathrm{z}$ for $\mathrm{FB}_{2}$. Quantitative determination was performed using LC-Quan 2.0 software (ThermoFisher). 
Both for aflatoxins and fumonisins, four replicates were analysed for each sample.

\section{Mass balance}

Both for aflatoxins and fumonisins, mass balances of the cleaning step [ Lamount $_{\text {(cleaning }}$ waste+cleaned maize)/amount (unprocessed $\left._{\text {maize) }}\right]^{* 100,}$ of the de-germination process $\left[\sum\right.$ amount $_{(\text {animal feed flour-cleaning waste+grits+germ })} /$ amount $\left._{(\text {cleaned maize) }}\right] * 100$ and of the total milling process $\left[\sum \text { amount }_{(\text {animal feed flour+coarse grits+flours+germ) }} / \text { amount }_{(\text {unprocessed maize) }}\right]^{*} 100$, were calculated.

\section{Results and discussion}

Yields of the milling-corn fractions

Yields of the different fractions, calculated with an approximation of $1 \%$, are reported in Table 2. The two maize lots had different characteristics, maize 2 being visually dustier and with a higher amount of broken kernels with respect to maize 1; as a consequence, the cleaning waste was 6 vs. $3 \%$ of the processed product for maize 2 and 1, respectively. Further, maize 2 yielded a lower amount of undersized flour deriving from the turbo sifter, with respect to maize 1 (17 vs. 20\%). As a consequence, the yield of animal feed flour was the same for maize 1 and $2(28 \%)$. For both maize lots, the ratio between coarse and fine flour, after refining of fine grits, was 85:15.

[insert Table 2 about here]

Performance of the methods

Recovery percentages were evaluated by spiking known blank samples at levels of 2 


\section{Aflatoxin distribution}

$\mathrm{AFB}_{1}$ and $\mathrm{AFG}_{1}$ were detected in both maize lots, but $\mathrm{AFB}_{2}$ and $\mathrm{AFG}_{2}$ only in maize 2 (Table 3). The $\mathrm{AFB}_{1}$ level of maize $1\left(3.6 \mu \mathrm{g} \mathrm{kg}^{-1}\right)$ was lower than the value fixed by EC Regulation 1881/2006 for unprocessed maize $\left(5 \mu \mathrm{g} \mathrm{kg}^{-1}\right)$; however, considering the final products, only coarse flour was within the limit for human consumption $(2 \mu \mathrm{g}$ $\mathrm{kg}^{-1}$ ), while coarse and fine grits slightly exceeded this limit. After the cleaning steps, maize 1 showed an $\mathrm{AFB}_{1}$ concentration slightly lower than the unprocessed one (3.3 against $3.6 \mu \mathrm{g} \mathrm{kg}^{-1},-8 \%$ ). Bran and germ deriving from de-cortication and degermination steps, resulted as more contaminated than cleaned maize $(+127$ and $+197 \%$, respectively). Animal feed flour, that included cleaning waste, bran, and undersized flour ground together, showed an $\mathrm{AFB}_{1}$ level close to raw maize. The results obtained for maize 1 basically accord with those reported by Brera et al. (2006): processing two maize lots with an $\mathrm{AFB}_{1}$ concentration below $3 \mu \mathrm{g} \mathrm{kg}^{-1}$, they observed an increase of contamination in bran, germ and animal feed flour and a consequent decrease in grits and flour destined for human consumption, that showed values below $2 \mu \mathrm{g} \mathrm{kg}^{-1}$. 
Maize 2 was much more contaminated $\left(91.1 \mu \mathrm{g} \mathrm{kg}^{-1}\right)$; after cleaning it showed an $\mathrm{AFB}_{1}$ level decidedly lower $\left(39.5 \mu \mathrm{g} \mathrm{kg}^{-1}\right)$ with respect to the unprocessed one $(-57 \%)$, as cleaning steps removed the most contaminated fractions (broken kernels, dust, etc.). Bran and germ of maize 2 showed much higher $\mathrm{AFB}_{1}$ concentrations $(+379$ and $+629 \%$, respectively) compared to cleaned maize. As a consequence, unlike maize 1 , the contamination level decreased remarkably in grits $(-80 \%)$ and increased $(+141 \%$ with respect to raw maize) in animal feed flour; however, the latter could not be used, as the value $\left(0.219 \mathrm{mg} \mathrm{kg}^{-1}\right)$ exceeded the limit of $0.02 \mathrm{mg} \mathrm{kg}^{-1}$ in force in the EU (Commission of the European Communities 2002). None of the milling-corn fractions destined for human consumption showed a concentration below the legal limit $(2 \mu \mathrm{g}$ $\mathrm{kg}^{-1}$ ), but they could be used as feeds. Considering the $\mathrm{AFB}_{1}$ percent distribution (Table 3 ), it is evident that cleaning steps led to very different results for the two maize lots, removing 11 vs. 59\% of the toxin from maize 1 and 2, respectively. Analogously, very different results were observed in de-cortication and de-germination steps; toxin removal was 30 vs. $72 \%$ for cleaned maize 1 and 2 , respectively. Consequently, the $\mathrm{AFB}_{1}$ percentage remaining in coarse and fine grits, was 55 vs. $13 \%$, for cleaned maize 1 and 2, respectively. Fine grits were subsequently processed to obtain coarse and fine flour, in the ratio $85: 15$; for maize $1,61 \%$ of the $\mathrm{AFB}_{1}$ amount in fine grits $(7.2 \%$ of the total) was present in coarse flour and $16.1 \%$ in fine flour; for maize 2, the corresponding percentages were 64.3 and $9.0 \%$. The lower figure was due to a small amount of remaining germ fraction (about $1 \%$ of unprocessed maize), more contaminated, that was removed in this step of the process. The different $\mathrm{AFB}_{1}$ percentage (26.4\% against $67.5 \%$ for maize 1 and 2 , respectively) collected in animal feed flour, was mainly due to the different contribution made by the waste of the 
cleaning steps.

A similar trend was observed for the other aflatoxins.

[insert Table 3 about here]

\section{Fumonisin distribution}

Both maize lots turned out to be contaminated with $\mathrm{FB}_{1}$ and $\mathrm{FB}_{2}$ (Table 4) at levels exceeding the limit (4000 $\mathrm{g} \mathrm{kg}^{-1}$ ) in force in the EU. Maize grains obtained after cleaning steps showed fumonisin concentrations lower (especially maize 2) than the unprocessed ones $\left(-11\right.$ and $-34 \%$ for $\left.\mathrm{FB}_{1}\right)$. Bran showed higher contamination levels with respect to cleaned maize $\left(+50\right.$ and $+167 \%$ for $\left.\mathrm{FB}_{1}\right)$; germ turned out to be less contaminated with respect to bran in both maize lots. Coarse and fine grits, fractions intended for human consumption, showed much lower $\mathrm{FB}_{1}$ concentrations when compared to cleaned maize ( -90 and $-88 \%$ for maize 1 and -90 and $-73 \%$ for maize 2 ). Besides, fine grits and fine flours, showed a level higher than the coarse ones. Therefore, as already found by Brera et al. (2004), contamination increases in lower particle size final products. Coarse grits for both maize lots, fine grits and coarse flour for maize 1, showed a contamination level $\left(\mathrm{FB}_{1}+\mathrm{FB}_{2}\right)$ below $1400 \mu \mathrm{g} \mathrm{kg}{ }^{-1}$, which is the limit fixed by the EU. Animal feed flour, which collected bran and cleaning waste, was three times more contaminated than unprocessed maize. Contamination levels found in different corn-milling fractions were similar to those found in previous studies (Katta et al., Broggi et al., Brera et al.), in which there was always reported an increase of concentration in bran, germ and animal feed flour and a decrease in products intended for human consumption, like grits and flours. As regards the $\mathrm{FB}_{1}$ percentage 
distribution, the cleaning plant removed $14 \%$ and $38 \%$ of the toxin for maize 1 and 2, respectively; regarding cleaned maize, de-cortication and de-germination processes removed altogether $12 \%$ and $27 \%$ of the toxin, while $6.8 \%$ and $8.8 \%$ remained in coarse and fine grits. It is evident that the highest fraction of $\mathrm{FB}_{1}$ remained in the undersized flour separated from the turbo sifter and conveyed into animal feed flour; this product gathers 83.3 and $90.9 \%$ of the total $\mathrm{FB}_{1}$ present in uncleaned maize 1 and 2 , respectively. A similar trend has been observed for $\mathrm{FB}_{2}$.

[insert Table 4 about here]

\section{Mass balance}

Mass balances of aflatoxins and fumonisins for the cleaning step, for the degermination process and for the complete process are reported in Table 5. The mass balance of the complete process for $\mathrm{AFG}_{1}$ in maize 1 was relatively low (79.3\%), probably because of a high analytical error associated with the low level of the mycotoxin; except for this result, mass balances of mycotoxins in both processes were in the range $90-110 \%$. Thus, it can be concluded that the dynamic sampling was effective and the results were altogether accurate.

[insert Table 5 about here]

\section{Conclusions}

The extent of decontamination obtained from the cleaning step was decidedly higher for a "dirty" maize (maize 2) with respect to a "normal" maize (maize 1). In this step, the 
percent toxin reduction in maize 2 , if calculated in terms of both concentration and mass, was $57-59 \%$ and $34-38 \%$ for $\mathrm{AFB}_{1}$ and $\mathrm{FB}_{1}$, respectively. For maize 1 , the corresponding values were $8-11 \%$ and $11-14 \%$ for $\mathrm{AFB}_{1}$ and $\mathrm{FB}_{1}$, respectively. The extent of decontamination obtained from the cleaning step of maize 2, was higher for aflatoxins than for fumonisins. Probably, during harvesting, handling and transportation, a fraction of the aflatoxin contaminated kernels broke and produced powder; therefore their removal contributed significantly to decontamination. For maize 2, discarding of the cleaning waste would decrease the yield of animal feed flour from $28 \%$ to $22 \%$, but the total amount of $\mathrm{AFB}_{1}$ and $\mathrm{FB}_{1}$ residual in the product would decrease from $67.5 \%$ to $8.2 \%$ and from $90.9 \%$ to $53.2 \%$, respectively. Generally, it is evident that an alternative use of cleaning waste would substantially improve the quality of animal feed flour.

As regards products after the cleaning step, a different distribution of the two toxins was observed. There was a large amount of $\mathrm{AFB}_{1}$ in the germ fraction, of $18.5 \%$ and $46.7 \%$ of the total for maize 1 and 2, respectively; for bran the corresponding values were $11.8 \%$ and $25.6 \%$; most of the remaining $\mathrm{AFB}_{1}$ was in coarse grits. As regards $\mathrm{FB}_{1}$, $4.3 \%$ and $12.7 \%$ occurred in germ, $7.7 \%$ and $14.1 \%$ in bran, for maize 1 and 2 , respectively; the amount remaining in coarse grits was low (5.5-5.6\%), while most was collected in undersized flour (81-64\%), that was intended for animal feed. It is evident that aflatoxin contamination of maize kernels was more superficial and concerned mainly the germ, while fumonisin contamination affected the inner layers of kernels. 


\section{References}

Abbas, H., Williams, W., Windham, G., Pringle, H., Xie, W., Shier, W. 2002. Aflatoxin and fumonisin contamination of commercial corn (Zea mays) hybrids in Mississippi. Journal of Agricultural and Food Chemistry 50(18): 5246-5254.

Adejumo, T., Hettwer, U., Karlovsky, P. 2007. Survey of maize from south-western Nigeria for zearalenone, $\alpha$ and $\beta$ zearalenols, fumonisin $\mathrm{B}_{1}$ and enniatins produced by Fusarium species. Food Additives and Contaminants 24(9): 993-1000.

Ali, N., Sardjono, Yamashita, A., Yoshizawa, T. 1998. Natural co-occurrence of aflatoxins and Fusarium mycotoxins (fumonisins, deoxynivalenol, nivalenol and zearalenone) in corn from Indonesia. Food Additives and Contaminants 15(4): 377-384.

AOAC International. 2005. Natural Toxins. Aflatoxins. Official Methods of Analysis of the International Association of Official Analytical Chemists. Gaithersburg, MD: AOAC. p. 4.

Battilani, P., Scandolara, A., Barbano, C., Pietri, A., Bertuzzi, T., Marocco, A., Berardo, N., Vannozzi, G.P., Baldini, M., Miele, S., Salera, E., Maggiore, T. 2005. Monitoraggio della contaminazione da micotossine in mais. L'Informatore Agrario 6:47-49.

Brera, C., Debegnach, F., Grossi, S., Miraglia, M. 2004. Effect of industrial processing on the distribution of fumonisin $\mathrm{B}_{1}$ in dry-milling corn fractions. Journal of Food Protection 67 (6): 1261-1266.

Brera, C., Catano, C., De Santis, B., Debegnach, F., De Giacomo, M., Pannunzi, E., Miraglia, M. 2006. Effect of industrial processing on the distribution of aflatoxins 
and zearalenone in corn-milling fractions. Journal of Agricultural and Food Chemistry 54: 5014-5019.

Broggi, L.E., Resnik, S.L., Pacin, A.M., Gonzalez, H., Cano, G., Taglieri, G. 2002. Distribution of fumonisins in dry-milled corn fractions in Argentina. Food Additives and Contaminants 19 (5):465-469.

Commission of the European Communities. 2002. Commission Directive 2002/32/EC of 7 May 2002 setting maximum levels for undesirable substances in animal feed. Official Journal of the European Communities L 140: 10-21.

Commission of the European Communities. 2006a. Commission regulation (EC) No. 1881/2006 of 19 December 2006 setting maximum levels for certain contaminants in foodstuffs. Official Journal of the European Union L 364: 5-24.

Commission of the European Communities. 2006b. Commission regulation (EC) No. 401/2006 of 23 February 2006 laying down the methods of sampling and analysis for the official control of the levels of mycotoxins in foodstuffs. Official Journal of the European Union L 70: 12-29.

Commission of the European Communities 2007. Commission regulation (EC) No. 1126/2007 of 28 September 2007 amending Regulation (EC) No 1881/2006 setting maximum levels for certain contaminants in foodstuffs as regards Fusarium toxins in maize and maize products. Official Journal of the European Union L 255: 14-17.

Domijan, A., Peraica, M., Jurjevic, Z., Ivic, D., Cvjetkovic, B. 2005. Fumonisin B1, fumonisin B2, zearalenone and ochratoxin A contamination of maize in Croatia. Food Additives and Contaminants 22(7): 677-680. 
Gonzalez, H., Martinez, E., Pacin, A., Resnik, S., Sydenham, E. 1999. Natural cooccurrence of fumonisins, deoxynivalenol, zearalenone and aflatoxins in field trial corn in Argentina. Food Additives and Contaminants 16(12): 565-569.

International Agency for Research on Cancer (IARC). 1993. Some naturally occurring substances, food items and constituents, heterocyclic aromatic amines and mycotoxins. IARC Monographs on the Evaluation of Carcinogenic Risk to Humans No. 56. Lyon: IARC: aflatoxins p.245; Fusarium verticillioides toxins p.445.

International Agency for Research on Cancer (IARC). 2002. Summaries \& Evaluations No. 82. Lyon: IARC: fumonisin $B_{1}$ p.301.

Istat 2006.Available:www.istat.it/agricoltura/datiagri/coltivazioni/anno2006/corg2006. Accessed 02 October 2007.

Katta, S.K., Cagampang, A.E., Jackson, L.S., Bullerman, L.B. 1997. Distribution of Fusarium molds and fumonisins in dry-milled corn fractions. Cereal Chemistry 74 (6): $858-863$.

Logrieco, A., Mulè, G., Moretti, A., Bottalico, A. 2002. Toxigenic Fusarium species and mycotoxins associated with maize ear rot in Europe. Mycotoxins in Plant Disease. European Journal of Plant Pathology, edited by A. Logrieco, J.A. Bailey, L. Corazza \& B.M. Cooke (Dordrecht:Kluver), 597-609.

Missmer, S.A., Suarez, L., Felkner, M., Wang, E., Merrill, A.H., Rothman, K.J., Hendricks, K.A. 2006. Exposure to fumonisins and the occurrence of neural tube defects along the Texas-Mexico border. Environmental Health Perspectives 114(2): $237-241$. 
Pietri, A., Bertuzzi, T., Pallaroni, L., Piva, G. 2004. Occurrence of mycotoxins and ergosterol in maize harvested over 5 years in Northern Italy. Food Additives and Contaminants $21(5): 479-487$.

Stroka, J., Petz, M., Joerissen, U., Anklam, E. 1999. Investigation of various extractants for the analysis of aflatoxin $\mathrm{B}_{1}$ in different food and feed matrices. Food Additives and Contaminants 16 (8): 331-338.

Sun, G., Wang, S., Hu, X., Su, J., Huang, T., Yu, J., Tang, L., Gao, W., Wang, J. 2007. Fumonisin $\mathrm{B}_{1}$ contamination of home-grown corn in high risk areas for esophageal and liver cancer in China. Food Additives and Contaminants 24 (2): $181-185$.

Sydenham, E.W., Thiel, P.G., Marasas, W.F.O., Shephard, G.S., Van Schalkwyk, D.J., Koch, K.R. 1990. Natural occurrence of some Fusarium mycotoxin in corn from low and high esophageal cancer prevalence areas of the Transkei, Southern Africa. Journal Agriculture Food Chemistry 38: 1900-1903.

Vargas, E., Preis, R., Castro, L., Silva, C. 2001. Co-occurrence of aflatoxins B , $_{2}, \mathrm{G}_{1}$, $\mathrm{G}_{2}$, zearalenone and fumonisin $\mathrm{B}_{1}$ in Brazilian corn. 2001. Food Additives and Contaminants 18(11): 981-986.

Visconti, A., Solfrizzo, M., Girolamo, A. de. 2001. Determination of fumonisins $B_{1}$ and $\mathrm{B}_{2}$ in corn and corn flakes by liquid chromatography with immunoaffinity column cleanup: collaborative study. Journal of AOAC International 84 (6): 1828-1837.

Voss, K., Riley, R., Norred, W.P., Bacon, C.W., Meredith, F., Howard, P., Plattner, R., Collins, T., Hansen, D., Porter, J. 2001. An overview of rodent toxicities: liver an kidney effects of fumonisins and Fusarium moniliforme. Environmental Health Perspectives 109, suppl.2: 259-266. 
Table 1. EU maximum admissible limits for $\mathrm{AFB}_{1}$, total aflatoxins (sum of $\mathrm{AFB}_{1}$, $\mathrm{AFB}_{2}, \mathrm{AFG}_{1}, \mathrm{AFG}_{2}$ ) and fumonisins (sum of $\mathrm{FB}_{1}$ and $\mathrm{FB}_{2}$ ) in maize and derived products.

\begin{tabular}{|c|c|c|c|}
\hline & $\begin{array}{c}\mathrm{AFB}_{1} \\
\left(\mu \mathrm{g} \mathrm{kg}^{-1}\right)\end{array}$ & $\begin{array}{c}\text { Sum of } \mathrm{AFB}_{1}, \mathrm{AFB}_{2}, \\
\mathrm{AFG}_{1} \text { and } \mathrm{AFG}_{2} \\
\left(\mu \mathrm{g} \mathrm{kg}^{-1}\right)\end{array}$ & $\begin{array}{l}\text { Sum of } \mathrm{FB}_{1} \\
\text { and } \mathrm{FB}_{2} \\
\left(\mu \mathrm{g} \mathrm{kg}^{-1}\right)\end{array}$ \\
\hline Unprocessed maize & 5.0 & 10.0 & 4000 \\
\hline $\begin{array}{l}\text { Maize for direct human } \\
\text { consumption }\end{array}$ & 2.0 & 4.0 & 1000 \\
\hline Maize-based breakfast & - & - & 800 \\
\hline $\begin{array}{l}\text { Milling fractions of maize wit } \\
\text { particle size }>500 \text { micron }\end{array}$ & & - & 1400 \\
\hline $\begin{array}{l}\text { Milling fractions of maize wit } \\
\text { particle size \# } 500 \text { micron }\end{array}$ & & - & 2000 \\
\hline
\end{tabular}


Table 2. Yield of maize milling fractions.

\begin{tabular}{|c|c|c|}
\hline Maize milling fractions & Yield maize 1 (\%) & Yield maize 2 (\%) \\
\hline Unprocessed maize & 100 & 100 \\
\hline Waste of aspirator & 2 & 3 \\
\hline Waste of dust filter & 0,2 & 1,5 \\
\hline Waste of intensive scourer & 0,8 & 1,5 \\
\hline Cleaned maize & 97 & 94 \\
\hline Bran & 5 & 6 \\
\hline Germ & 6 & 55 \\
\hline Coarse grits & 55 & 11 \\
\hline Fine grits & 11 & 85 \\
from which: & 85 & 15 \\
\hline coarse flour \\
fine flour & 15 & 17 \\
\hline Undersized flour & 20 & 28 \\
\hline $\begin{array}{c}\text { Animal feed flour } \\
\text { (waste+bran+undersized flour) }\end{array}$ & 28 & \\
\hline
\end{tabular}


Table 3: Aflatoxin levels (mean of 4 replicates, $\mu \mathrm{g} \mathrm{kg}^{-1}$ ), relative standard deviation (RSD, \%) and $\mathrm{AFB}_{1}$ relative distribution (\%) in maize-milling fractions referred to unprocessed maize and (between parentheses) to cleaned maize.

\begin{tabular}{|c|c|c|c|c|c|c|c|c|c|c|c|c|c|c|}
\hline \multirow[t]{3}{*}{ Maize-milling fractions } & \multicolumn{5}{|c|}{ Maize 1} & \multicolumn{9}{|c|}{ Maize 2} \\
\hline & \multicolumn{3}{|c|}{$\mathrm{AFB}_{1}$} & \multicolumn{2}{|c|}{$\mathrm{AFG}_{1}$} & \multicolumn{3}{|c|}{$\mathrm{AFB}_{1}$} & \multicolumn{2}{|c|}{$\mathrm{AFB}_{2}$} & \multicolumn{2}{|c|}{$\mathrm{AFG}_{1}$} & \multicolumn{2}{|c|}{$\mathrm{AFG}_{2}$} \\
\hline & $\mu \mathrm{g} \mathrm{kg}^{-1}$ & $\begin{array}{c}\mathrm{RSD} \\
\%\end{array}$ & $\begin{array}{c}\text { Distribution } \\
\%\end{array}$ & $\mu \mathrm{g} \mathrm{kg}^{-1}$ & $\begin{array}{c}\text { RSD } \\
\%\end{array}$ & $\mu \mathrm{g} \mathrm{kg}^{-1}$ & $\begin{array}{c}\mathrm{RSD} \\
\%\end{array}$ & $\begin{array}{c}\text { Distribution } \\
\%\end{array}$ & $\mu \mathrm{g} \mathrm{kg}^{-1}$ & $\begin{array}{c}\mathrm{RSD} \\
\%\end{array}$ & $\mu \mathrm{g} \mathrm{kg}^{-1}$ & $\begin{array}{c}\mathrm{RSD} \\
\%\end{array}$ & $\mu \mathrm{g} \mathrm{kg}^{-1}$ & $\begin{array}{c}\mathrm{RSD} \\
\%\end{array}$ \\
\hline Unprocessed maize & 3.6 & 11.1 & 100 & 1.7 & 5.9 & 91.1 & 3.8 & 100 & 3.4 & 8.8 & 26.3 & 1.5 & 1.1 & 9.1 \\
\hline Waste of aspirator & 3.4 & 11.8 & 1.9 & 1.8 & 11.1 & 138.3 & 3.9 & 4.6 & 38.1 & 3.4 & 26.3 & 9.5 & 1.6 & 12.5 \\
\hline Waste of dust filter & 17 & 9.4 & 1.0 & 8.3 & 8.4 & 1296 & 2.0 & 21.3 & 57.8 & 2.4 & 290.3 & 2.3 & 9.1 & 5.5 \\
\hline Waste of intensive scourer & 11.5 & 12.2 & 2.6 & 6.1 & 8.2 & 1554 & 0.8 & 25.6 & 54.5 & 2.9 & 285.5 & 2.5 & 9.4 & 5.3 \\
\hline Cleaned maize & 3.3 & 15.1 & $\begin{array}{c}88.7 \\
(100)\end{array}$ & 1.1 & 9.1 & 39.5 & 6.1 & $\begin{array}{c}40.7 \\
(100) \\
\end{array}$ & 1.8 & 11.1 & 13.9 & 4.3 & 0.7 & 14.3 \\
\hline Bran & 7.5 & 9.3 & $\begin{array}{c}10.5 \\
(11.8)\end{array}$ & 3.9 & 7.7 & 189.4 & 4.5 & $\begin{array}{c}10.4 \\
(25.6)\end{array}$ & 7.3 & 10.9 & 42.7 & 3.5 & 1.1 & 9.1 \\
\hline Germ & 9.8 & 9.2 & $\begin{array}{c}16.4 \\
(18.5)\end{array}$ & 5.2 & 9.6 & 287.9 & 1.0 & $\begin{array}{c}19.0 \\
(46.7)\end{array}$ & 16.7 & 3.0 & 81.9 & 1.5 & 5.0 & 6.0 \\
\hline Coarse grits & 2.7 & 11.1 & $\begin{array}{c}41.7 \\
(47.0) \\
\end{array}$ & 1.1 & 9.1 & 7.6 & 3.9 & $\begin{array}{c}4.6 \\
(11.3) \\
\end{array}$ & 0.4 & 25.0 & 1.9 & 5.3 & 0.3 & 16.7 \\
\hline $\begin{array}{l}\text { Fine grits } \\
\text { from which: }\end{array}$ & 2.3 & 8.7 & $\begin{array}{c}7.2 \\
(8.1)\end{array}$ & 1.0 & 10 & 7.8 & 5.1 & $\begin{array}{c}0.9 \\
(2.2)\end{array}$ & 0.7 & 14.3 & 2.4 & 8.3 & 0.6 & 16.7 \\
\hline coarse flour & 1.7 & 11.8 & 61.0 & 0.8 & 12.5 & 5.9 & 5.1 & 64.3 & 0.6 & 16.7 & 2.0 & 10.0 & 0.5 & 10.0 \\
\hline fine flour & 2.5 & 12.0 & 16.1 & 1.2 & 8.3 & 4.7 & 6.4 & 9.0 & 0.5 & 20.0 & 1.4 & 14.3 & 0.4 & 12.5 \\
\hline Animal feed flour & 3.4 & 11.8 & 26.4 & 1.1 & 9.1 & 219.6 & 2.5 & 67.5 & 8.8 & 3.4 & 48.5 & 7.4 & 1.7 & 11.8 \\
\hline
\end{tabular}


Table 4: Fumonisin levels (mean of 4 replicates, $\mu \mathrm{g} \mathrm{kg}^{-1}$ ), relative standard deviation (RSD, \%) and $\mathrm{FB}_{1}$ relative distribution (\%) in corn-milling fractions referred to unprocessed maize and (between parentheses) to cleaned maize.

\begin{tabular}{|c|c|c|c|c|c|c|c|c|c|c|}
\hline \multirow[t]{3}{*}{ Maize-milling fractions } & \multicolumn{5}{|c|}{ Maize 1} & \multicolumn{5}{|c|}{ Maize 2} \\
\hline & \multicolumn{3}{|c|}{$\mathrm{FB}_{1}$} & \multicolumn{2}{|c|}{$\mathrm{FB}_{2}$} & \multicolumn{3}{|c|}{$\mathrm{FB}_{1}$} & \multicolumn{2}{|c|}{$\mathrm{FB}_{2}$} \\
\hline & $\mu \mathrm{g} \mathrm{kg}^{-1}$ & $\begin{array}{c}\mathrm{RSD} \\
\%\end{array}$ & $\begin{array}{c}\text { Distribution } \\
\%\end{array}$ & $\mu \mathrm{g} \mathrm{kg}^{-1}$ & $\begin{array}{c}\mathrm{RSD} \\
\%\end{array}$ & $\mu \mathrm{g} \mathrm{kg}^{-1}$ & $\begin{array}{c}\mathrm{RSD} \\
\%\end{array}$ & $\begin{array}{c}\text { Distribution } \\
\%\end{array}$ & $\mu \mathrm{g} \mathrm{kg}^{-1}$ & $\begin{array}{c}\mathrm{RSD} \\
\%\end{array}$ \\
\hline Unprocessed maize & 5379 & 10.5 & 100 & 2576 & 7.7 & 8841 & 7.9 & 100 & 4234 & 8.4 \\
\hline Waste of aspirator & 17353 & 4.6 & 6.4 & 6539 & 5.6 & 48425 & 5.5 & 16.5 & 11465 & 6.5 \\
\hline Waste of dust filter & 42222 & 2.9 & 1.6 & 31389 & 2.1 & 50872 & 3.7 & 8.7 & 34103 & 4.3 \\
\hline Waste of intensive scourer & 43402 & 2.8 & 6.4 & 24653 & 1.8 & 48565 & 3.0 & 8.3 & 24746 & 4.1 \\
\hline Cleaned maize & 4770 & 8.5 & $\begin{array}{c}86.0 \\
(100)\end{array}$ & 2360 & 6.7 & 5862 & 3.9 & $\begin{array}{c}62.3 \\
(100)\end{array}$ & 2975 & 5.3 \\
\hline Bran & 7154 & 5.3 & $\begin{array}{c}6.6 \\
(7.7) \\
\end{array}$ & 2559 & 6.5 & 15647 & 1.0 & $\begin{array}{c}8.8 \\
(14.1) \\
\end{array}$ & 5597 & 2.2 \\
\hline Germ & 3332 & 7.2 & $\begin{array}{c}3.7 \\
(4.3) \\
\end{array}$ & 1237 & 6.6 & 11674 & 8.1 & $\begin{array}{c}7.9 \\
(12.7) \\
\end{array}$ & 4334 & 8.2 \\
\hline Coarse grits & 458 & 11.1 & $\begin{array}{c}4.7 \\
(5.5)\end{array}$ & 128 & 11.7 & 563 & 8.0 & $\begin{array}{c}3.5 \\
(5.6) \\
\end{array}$ & 157 & 13.4 \\
\hline $\begin{array}{l}\text { Fine grits } \\
\text { from which: }\end{array}$ & 556 & 8.1 & $\begin{array}{c}1.1 \\
(1.3)\end{array}$ & 163 & 11.0 & 1592 & 2.8 & $\begin{array}{c}2.0 \\
(3.2)\end{array}$ & 500 & 8.4 \\
\hline coarse flour & 292 & 10.6 & 44.6 & 96 & 9.4 & 1266 & 7.5 & 67.6 & 416 & 7.9 \\
\hline & 1922 & 7.7 & 51.8 & 635 & 5.7 & 3058 & 5.8 & 28.8 & 2975 & 5.6 \\
\hline Animal feed flour & 16011 & 2.1 & 83.3 & 8155 & 3.7 & 28712 & 5.9 & 90.9 & 14624 & 2.4 \\
\hline
\end{tabular}

http://mc.manuscriptcentral.com/tfac Email: fac@tandf.co.uk 
Table 5: Aflatoxin and fumonisin mass balance (\%) for maize 1 and 2.

\begin{tabular}{|l|c|c|c|c|c|c|}
\hline \multicolumn{1}{|c|}{ Mass balance } & $\mathrm{AFB}_{1}$ & $\mathrm{AFB}_{2}$ & $\mathrm{AFG}_{1}$ & $\mathrm{AFG}_{2}$ & $\mathrm{FB}_{1}$ & $\mathrm{FB}_{2}$ \\
\hline $\begin{array}{l}\text { Cleaning step } \\
\text { Maize 1 } \\
\text { Maize 2 }\end{array}$ & 94.2 & - & 93.8 & - & 100.4 & 104.0 \\
\hline $\begin{array}{l}\text { De-germination process } \\
\text { Maize 1 } \\
\text { Maize 2 }\end{array}$ & 96.3 & 109.1 & 96.2 & 96.0 & 95.6 & 102.2 \\
\hline $\begin{array}{l}\text { Complete milling process } \\
\text { Maize 1 } \\
\text { Maize 2 }\end{array}$ & 99.5 & $\begin{array}{c}- \\
108.0\end{array}$ & $\begin{array}{c}110.0 \\
99.5\end{array}$ & $\begin{array}{c}- \\
99.5\end{array}$ & $\begin{array}{c}91.2 \\
114.6\end{array}$ & $\begin{array}{c}89.8 \\
106.1\end{array}$ \\
\hline
\end{tabular}

Figure 1. Layout of the industrial plant showing sampling points (numbered) and final products (bold type). 


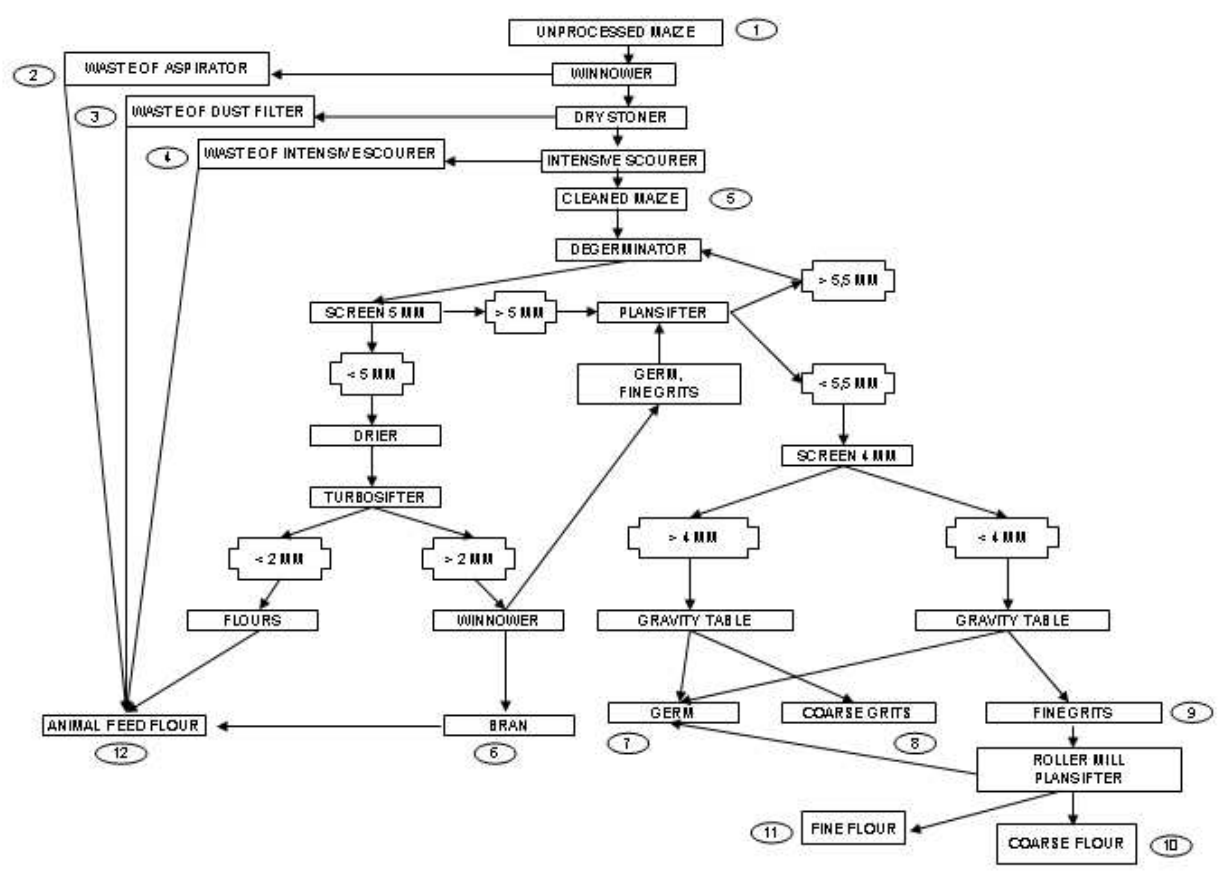

Figure 1.

Figure 1. Layout of the industrial plant showing sampling points (numbered) and final products (bold type).

$254 \times 190 \mathrm{~mm}(72 \times 72 \mathrm{DPI})$ 